\title{
Palm Oil Soil Monitoring System for Smart Agriculture
}

\section{Roziyani Rawi ${ }^{1}$, Muhammad Shakhil Iman Hasnan², Aznida Abu Bakar Sajak}

\author{
${ }^{1}$ MIIT, Universiti Kuala Lumpur, Kuala Lumpur, 50250, MALAYSIA \\ ${ }^{2}$ MIIT, Universiti Kuala Lumpur, Kuala Lumpur, 50250, MALAYSIA \\ ${ }^{3}$ MIIT, Universiti Kuala Lumpur, Kuala Lumpur, 50250, MALAYSIA \\ University of Liverpool, United Kingdom (Great Britain)
}

*Corresponding Author

DOI: https://doi.org/10.30880/ijie.2020.12.06.022

Received 22 February 2020; Accepted 19 July 2020; Available online 30 July 2020

\begin{abstract}
Palm oil is among the first commodity in Malaysia. The production of palm oil can be increased by implementing smart agriculture technology. To produce a good quality of palm oil, good soil quality is vital. Lack of soil information can make it hard for the farmer to maintain the nutritious of the oil palm tree. Thus, a real-time palm oil soil monitoring system has been developed for Palm Oil Soil Monitoring in a Smart Agriculture. The system measured the $\mathrm{pH}$, moisture and tilt of palm oil soil. These parameters were essential to determine the palm oil soil status of alkalinity, tilt and moisture. These sensors are connected to Arduino microcontroller, which captures, processes and analyses the data. The captured data will be sent via the WiFi connectivity to the cloud database for the record. Based on the data analysis, the quality of the soil will be determined for further action by the farmer. The results showed that the system had successfully processed, transmitted, displayed and concluded the soil's status. As a result, real-time reading will be displayed in the graphical graph using ThingSpeak.
\end{abstract}

Keywords: IoT, Smart Agriculture, pH sensor, moisture sensor, tilt sensor

\section{Introduction}

Agriculture remains an essential part of Malaysia's economy, contributing 12 percent of the national GDP and providing employment for 16 percent of the total population. Low quality of palm oil soil can affect the quality of oil palm tree productivity [Appendix 1]. In addition, the lack of soil information can make it hard for the farmer to maintain the nutritious of the oil palm tree.

In [1], a real-time monitoring system for greenhouse had been developed to collect a dynamic and real-time data of a landscape. In this project, temperature, humidity, soil moisture were monitored, and the information was sent via GSM.

In [2], a solution to monitor soil's condition measurement for oil palm plantation called PalmNet has been developed. The system is using WSN technology which used to compose the soil's condition measurement, and the data visualization can be accessed via a web-server interface. Soil's moisture data that are collected using two sensor nodes, a sink and a gateway were sent to web-server through ZigBee network using GPRS module.

In [3], a smart irrigation system for agriculture land has been developed using Rasberry Pi, which will allow the farmer to monitor their field status from anywhere. The aim of the project was to optimize water use for the agricultural crop by allowing controlling water motor automatically. Results from moisture sensor, water level sensor and weather API helps the water motor to control the water flow to the field.

In [4], to solve the difficulties of physical monitoring for outdoor locations such as paddies field and orchards, a system using a wireless sensor network had been developed. The integration of WSN sensors, CCTVs, GPS, database

*Corresponding author: roziyani@unikl.edu.my 
server, web server and DVR server makes the agriculture environmental is possible to be viewed managed using a graphic user interface.

While in [5], a solution to reduce the complexity of physical wiring, and maintenance for traditional wired communication in agriculture had been developed by adopting Zigbee technology in measuring the temperature and humidity. In addition, solar power had been implemented to replace ordinary lithium battery power supply. All collected data can be viewed via Webserver.

Lastly, in [6], a survey on different applications of Zigbee based wireless sensor network (WSN) in agriculture had been presented. The findings indicate that Zigbee sensor has communication protocol and power consumption issues in agriculture industries.

In this project, a device had been developed to detect the $\mathrm{pH}$ value, the moisture and the tilt of the palm oil's soil by using Internet of Things (IoT) technology which had given more precise and more efficient results compared to the existing tools used in [1-6]. The system was able to detect faster, accurate and notify the farmer to take immediate action in improving the soil quality, which will finally optimize the palm oil production.

This device had a pH sensor, moisture sensor and tilt sensor, which connected to a module called Arduino. Sensors sent the captured result to the Adruino, which acts as a microcontroller. The captured results are sent to the cloud database using WiFi. The farmer can view the real-time result in graph instantly using software called ThingSpeak.

For $\mathrm{pH}$ value, it primarily expressed with a numeric scale ranging from $0-14$. The acidity level is ranging from 0-6, while alkali is ranging from $8-11$. Neutral $\mathrm{pH}$ can be obtained when the numeric scale stops at 7 . The optimum $\mathrm{pH}$ level for palm oil soil is between 3.5 and above, as shown in the Appendix 1.

While moisture refers to the water present in the space between the soil particles, soil moisture influences the physical, chemical, and biological characteristics of the soil. Soil moisture is the percentage of moisture (on a weight basis) in a soil sample at any given time. It shows the general moisture content of the soil. According to the Appendix 1, the recommended soil moisture for palm oil is between $30 \%$ until $75 \%$.

As for tilt, in this project, it can refer to the level of inclination of soil. It used to measure the angles of slope. For Palm oil plantation, the recommended angles must be 25 degrees and below, as shown in the Appendix 1.

\section{Methodology}

RAD also is known as Rapid Application Model is used as a method for this project. During the initiation phase, all the information needed for this project was gathered, and the related projects were also reviewed. To inquire valid parameters for the palm oil soil, an interview with the Agronomist from TH Plantation had been conducted. The project's objective which to develop a monitoring system for palm oil soil for smart agriculture was determined. The physical design and logical design has been prepared to guide the implementation of the system. A physical connection from all devices including sensors, Adruino, Wi-Fi module and cloud database also being performed and verified. Three different soil samples were taken and tested using the system. The soil quality was tested based on the pH level, the moisture and the tilt. Some water was added to the soil samples to show the moisture sensor works. The result was sent to the cloud database wirelessly and can be viewed in real-time using ThingSpeak software in graph form. From the result, the system could conclude the quality of the soil.

Fig. 1 and Fig. 2 show the topology of the Palm Oil Soil System for Smart Agriculture and the block diagram. Arduino Uno has been used as the microcontroller for this project. The sensors needed in this project consist of $\mathrm{pH}$, moisture and tilt sensor. Wi-Fi module is used to send the results from microcontroller to the cloud database. The results were displayed in graph form and can be viewed by the farmer via smartphone using ThingSpeak software.

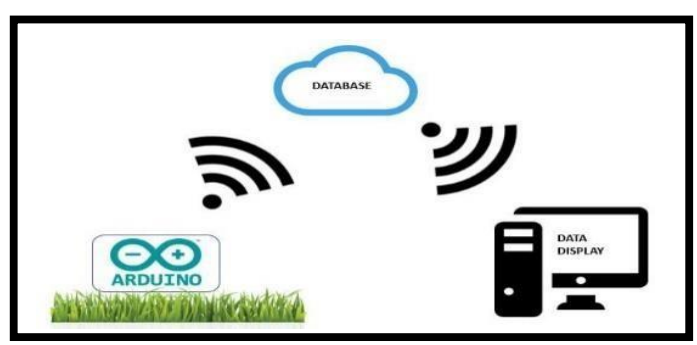

Fig. 1 - Topology of the Palm Oil Soil Monitoring System for Smart Agriculture 


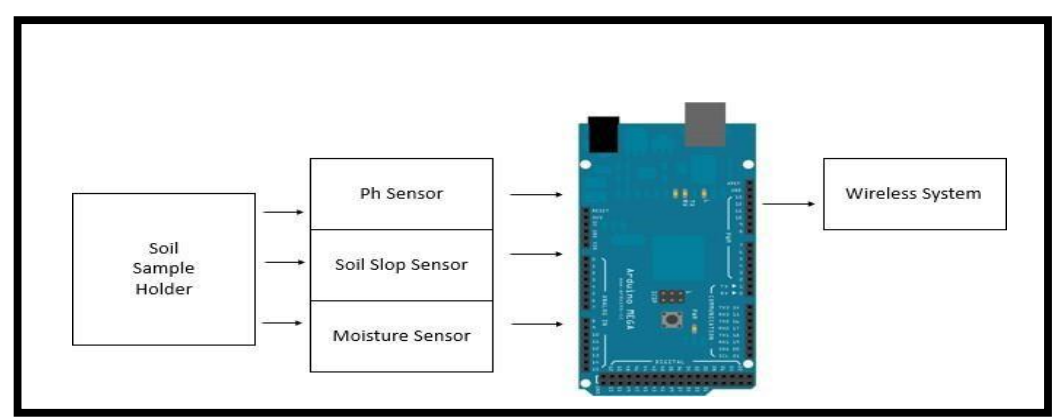

Fig. 2 - Block Diagram of the Project

\section{Hardware and Software}

Arduino Uno is used as the microcontroller for this project. The sensors needed in this project consist of a pH sensor, moisture sensor and Tilt sensor. Wi-Fi module is used to send results from the microcontroller to the cloud database. The results were sent to the ThingSpeak software, where the results will be shown on the smartphone in a graph form.

\subsection{Hardware}

\section{A. pH sensor}

$\mathrm{pH}$ sensor is a device used to measure the level of acidity or alkalinity of a solution. In this project, it measures the acidity or alkalinity of palm oil soil. The $\mathrm{pH}$ scale ranges from 0 to 14 . The $\mathrm{pH}$ indicates the concentration of hydrogen $[\mathrm{H}]+$ ions present in certain solutions. It can accurately be quantified by a sensor that measures the potential difference between two electrodes: a reference electrode (silver/silver chloride) and a glass electrode that is sensitive to hydrogen ion. This sensor gives an output in the form of an analogue signal. It requires ADC before connected to the Arduino. The accuracy of the sensor is $\pm 0.1 \mathrm{pH}$. For palm oil, the best $\mathrm{pH}$ value is between 3.5 and above.

\section{B. Moisture Sensor}

Moisture Sensor is used to detect the moisture of water contains in the soil. This sensor will read the soil moisture in the form of voltage. The higher the voltage indicates that the moisture of the soil is high. Then the value will be converted into a percentage to make it easier to read. From $0 \%$ to $25 \%$ show that the moisture is less in the soil while $70 \%$ an above show the moisture is high in the soil. The sensor will poke to the soil until it reaches the black part to take accurate value. For palm oil, the optimum moisture level is between $30 \%$ to $75 \%$.

\section{Tilt Sensor}

For this project, SN-ADXI335-CY tilt sensor model has been used. The tilt sensor is used to determine the soil's readiness for palm oil planting. The sensor has a full sensing range of $+/-3 \mathrm{~g}$.

\section{Arduino Uno}

The central controller used for this project is Arduino Uno. It is a microcontroller based on the ATmega2560. It has 54 digital input/output pins, 16 analogue inputs, a $16 \mathrm{MHz}$ quartz crystal, a USB connection, a power jack, an ICSP header, and a reset button. This board contains two power supplies that are $3.3 \mathrm{v}$ and $5 \mathrm{v}$. It also has two ground ports for safety. Five ports of analogue input are provided to connect to the three sensors. Digital input also has been provided to connect to the Wi-Fi module. Arduino Uno can be powered up by connecting the adapter to the power supply port. The Arduino can be managed by connecting USB type B to the USB port at the computer.

\section{E. Wi-Fi Module}

The ESP8266 Wi-Fi Module is a self-contained SOC with integrated TCP/IP protocol stack that can give any microcontroller access to the Wi-Fi network. The ESP8266 is capable of hosting an application or offloading all WiFi networking functions from another application processor. Each ESP8266 module comes pre-programmed with an AT command set firmware so that it can merely hook with an Arduino board and get about as much Wi-Fi-ability as a Wi-Fi Shield offers. The ESP8266 module is an extremely cost-effective board with a vast and ever-growing community [7].

This module has a powerful enough on-board processing and storage capability that allows it to be integrated with the sensors and other application-specific devices through its GPIOs with minimal development up-front and minimal loading during runtime. Its high degree of on-chip integration allows for minimal external circuitry, including the frontend module, is designed to occupy minimal PCB area. The ESP8266 supports APSD for VoIP applications and Bluetooth 
co-existence interfaces. It contains a self-calibrated RF allowing it to work under all operating conditions and requires no external RF parts [7].

\subsection{Software}

In this project development, three different software are required for successful implementation.

\section{A. ThingSpeak}

ThingSpeak is an IoT analytics platform service that allows storing data retrieved from the sensors. To use the ThingSpeak, ESP8266 need to be connected to the Wi-Fi network. Then, the channel needs to be created, and the Adruino will send the data to the ThingSpeak IP address and API Key.

\section{B. Arduino IDE}

Arduino is an open-source platform used for building electronics projects. It consists of both a physical programmable circuit board or a microcontroller and a piece of software, or IDE (Integrated Development Environment) that runs on a computer to write and upload computer code to the physical board.

\section{NetBean Java}

NetBeans is a Java-based, integrated development environment (IDE). The term also refers to the IDE's underlying application platform framework. The underlying NetBeans platform supports the creation of new applications and further development of existing applications using modular software components.

\subsection{Prototype Development and Testing}

Fig. 3 shows the flowchart of the Palm Oil Soil System for Smart Agriculture. During the development phase, all physical components are connected and configured. To start the configuration on Arduino Uno, it needs to be connected to a computer. The microcontroller will automatically be powered up once it is related to the USB port of the computer. Once connected, the Arduino IDE and related drivers need to be installed in the microcontroller.

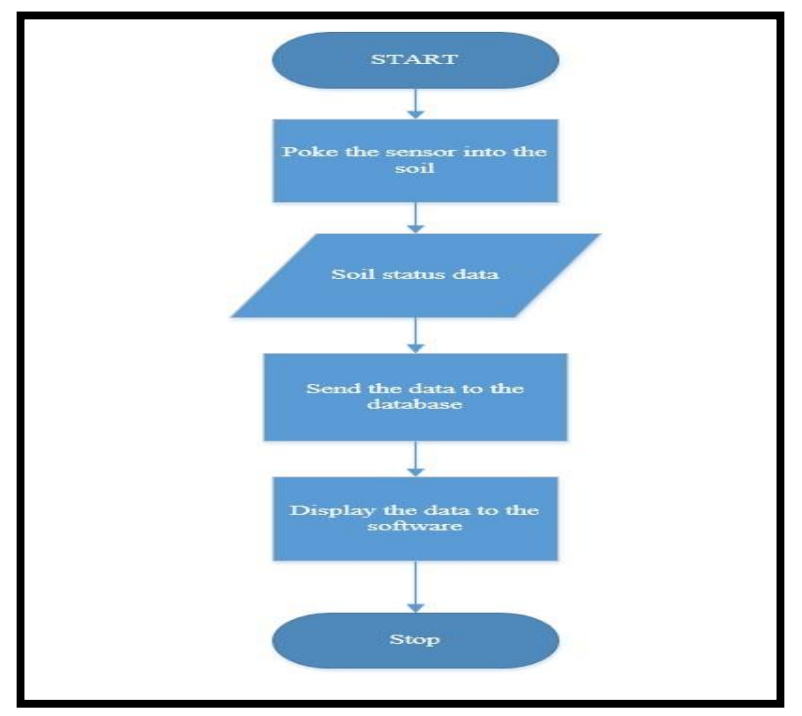

Fig. 3 - The Flowchart of Palm Oil Soil System for Smart Agriculture

Then, the sensors were poked in the soil sample. Once the sensors have the reading, it will then be sent to the microcontroller. The controller updates the database in the ThingSpeak via Wi-Fi module, and as a result, the farmer can see the soil status graph using a smartphone. If the connection between sensors and controller is not established, the data cannot be sent to the microcontroller as well as to the cloud database.

During the implementation phase, all the sensors need to be connected to the Arduino board. Fig. 4 and Fig. 5 shows how both sensors are connected to the Arduino board. For both $\mathrm{pH}$ sensor and moisture sensor, each of them was connecting three ports to the Arduino, which are VCC, GND and Voltage. For pH sensor, the results which were read in voltage are converted to $\mathrm{pH}$ value [table voltage to $\mathrm{pH}$ value]. If the $\mathrm{pH}$ value is below 3.5 , the soil is considered too 
acidic, for value between 3.5 until less than 7 ; the soil is considered as acidic while for value above 7 , indicating that the soil is alkaline and if the $\mathrm{pH}$ value is 7 , it indicates that the soil is neutral.

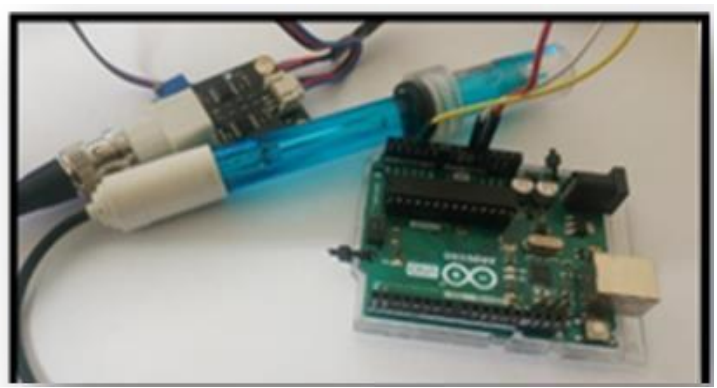

Fig. 4 - pH Sensor connected to the Arduino Board

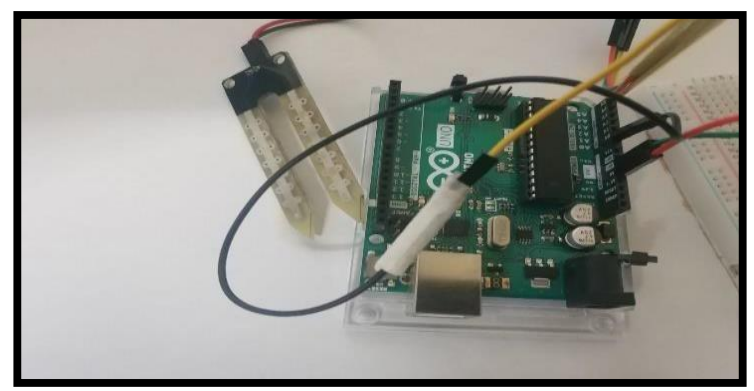

Fig. 5 - Moisture Sensor Connected to Arduino board

For moisture sensor, it reads the soil moisture in voltage form and the readings are converted to the percentage value. For reading in ranges between $0 \%$ to $25 \%$, it shows the soil moisture is less, while $70 \%$ an above shows the soil moisture is high.

As for the project testing, firstly, the farmer needs to establish a network between the sensors, Arduino, Wi-Fi module and the smartphone via Wi-Fi network. Once the connection is ready, three different soil samples are taken. To test the sensor functionality, the sensors are poked into the soils for a few minutes. Fig. 6 - 8 illustrate how the sensors were poked into the soil samples. The sensor remains in the soils until stable readings are achieved. To get an accurate result, the moisture sensor needs to be poked until it reaches the black part of the sensor. The sensors detect the soil status according to the function of $\mathrm{pH}$, moisture and tilt.

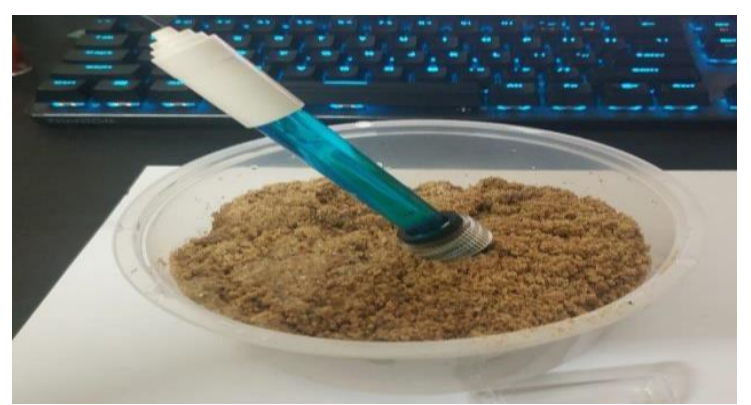

Fig. 6 - Poking the end of pH Probe into the Soil Sample

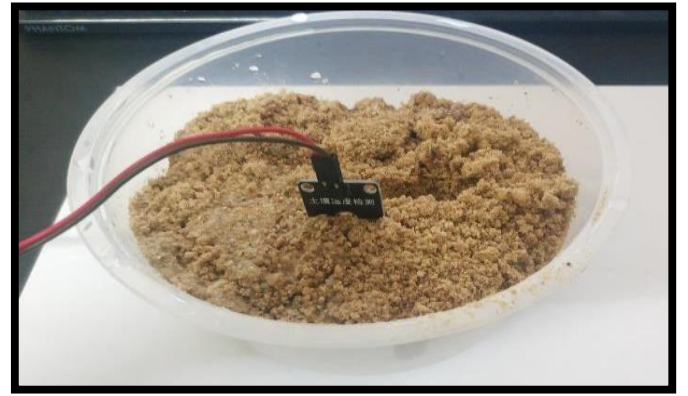

Fig. 7 - Poking the Moisture Sensor into the Soil Sample

Fig. 8 shows the positioning of a tilt sensor to ensure the $\mathrm{X}, \mathrm{Y}$ and $\mathrm{Z}$ axis are placed correctly on the soil surface. The indicator of the $\mathrm{X}, \mathrm{Y}$ and $\mathrm{Z}$ axis are shown on the tilt sensor board. To get an accurate result, the tilt sensor should be placed stand with the pin on the left side of the board.

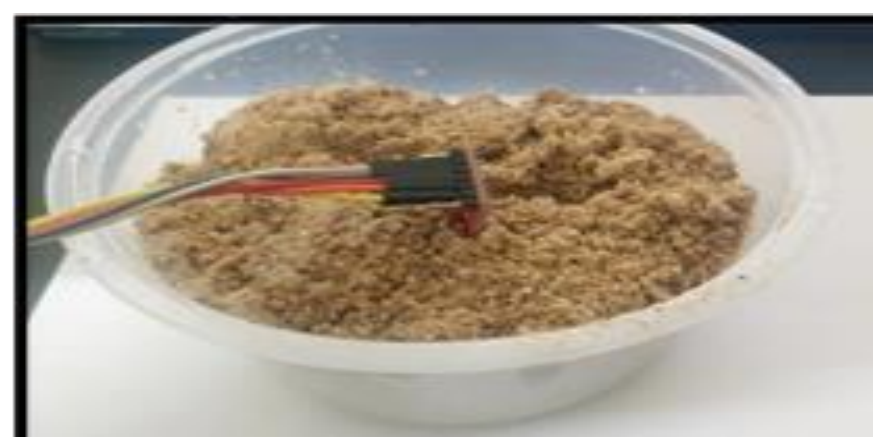

Fig. 8 - Positioning Tilt Sensor in the Soil Sample

To allow Arduino to transfer the result to the ThingSpeak, Wi-Fi module has been configured. SSID "FYP" is used to associate with wireless hotspot provided by the smartphone. 


\section{Results and Discussion}

To view the result, the end-user must be connected to the Wi-Fi network. The farmer must turn on the hotspot so the ESP8266 Wi-Fi module can be connected to the smartphone. When the connection was established, it allows the system to connect with ThingSpeak. The connection will establish automatically when the hotspot turned on. It is because the hotspot's SSID and password have been embedded in the Arduino to make the connection stable and reliable. The sensors' reading will be shown through the ThingSpeak application. Besides the graph, the previous soil status data can be viewed and monitored by the cloud database.

After the connection has established, $\mathrm{pH}$ probes, moisture and tilt sensor were poked in the soil samples, as shown in Fig. 6-8, the sensors detect the reading of the soil samples. Then the data will be sent to the microcontroller in the form of an analogue signal, which then will be converted to a digital signal by using Analog-Digital Converter (ADC). After the microcontroller receives the data, the data will be sent to the ThingSpeak application via the ESP8266 Wi-Fi module.

To test the functionality of the sensors, each sensor was poked into three different soils. The soils were tested to produce a different level of moisture, $\mathrm{pH}$ and tilt degree.

Table 1 - Partial Result Stored in the Cloud Database

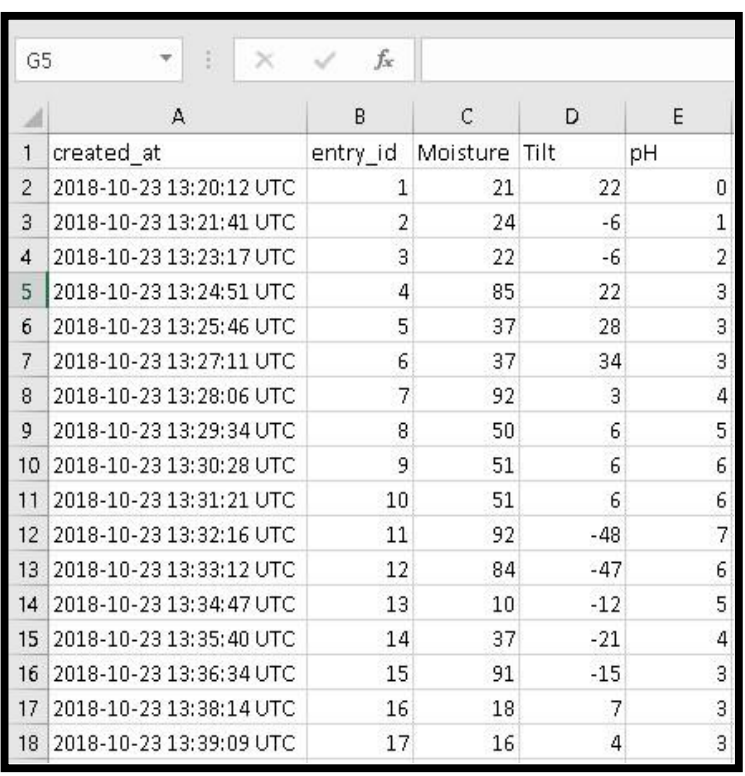

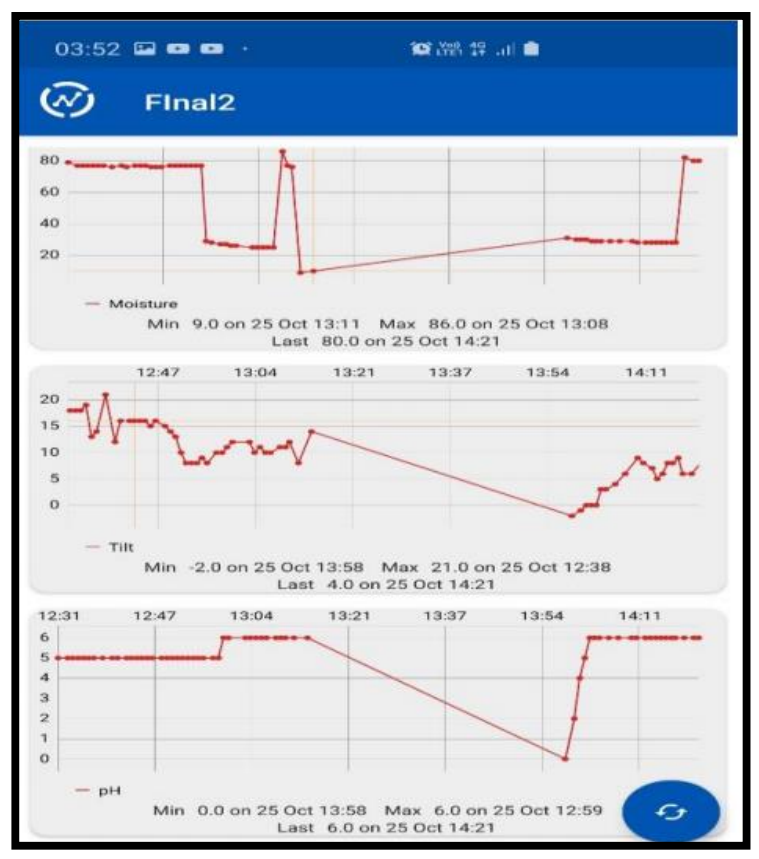

Fig. 15 - Overall Sensor Result is shown in ThingSpeak 
Table 1 shows the results retrieved from sensors stored in the cloud database. The third column, "Moisture" shows the reading in percentage value of the moisture sensor. The fourth column, "Tilt" shows the reading in degrees value of the tilt sensor. Lastly, for the fifth column, "pH" shows the reading of $\mathrm{pH}$ sensor either the soil is in an alkaline or acidic state. While Fig. 15 illustrates the overall result in graph form using ThingSpeak.

Table 2 - Moisture Sensor Result (Wet)

\begin{tabular}{|l|l|l|l|l|l|}
\hline 52 & $2018-10-2$ & 51 & 11 & -7 & 6 DRY \\
\hline 53 & $2018-10-2$ & 52 & 11 & -8 & 6 DRY \\
\hline 54 & $2018-10-2$ & 53 & 11 & -8 & 6 DRY \\
\hline 55 & $2018-10-2$ & 54 & 11 & -7 & 6 DRY \\
\hline 56 & $2018-10-2$ & 55 & 11 & -7 & 6 DRY \\
\hline 57 & $2018-10-2$ & 56 & 11 & -8 & 6 DRY \\
\hline 58 & $2018-10-2$ & 57 & 92 & 41 & 3 WET \\
\hline 59 & $2018-10-2$ & 58 & 83 & 41 & 1 WET \\
\hline 60 & $2018-10-2$ & 59 & 82 & 41 & 2 WET \\
\hline 61 & $2018-10-2$ & 60 & 82 & 41 & 5 WET \\
\hline 62 & $2018-10-2$ & 61 & 82 & 41 & 7 WET \\
\hline
\end{tabular}

Table 2 shows the result captured from the moisture sensor. The lowest moisture reading was $11 \%$, while the highest reading was $92 \%$. Referring to the Appendix, when the moisture reading is $30 \%$, and below, the soil is categorized as dry. For the readings of $75 \%$ and above, the soil is classified as wet. This status is not suitable due to air cannot get into the root, and as a result, the plant will die within 6 months. Therefore, the action needs to be taken by the workers is use a water pump to suck the water out from plantation to the river. This corresponds to the method explained in Section 3.1 .

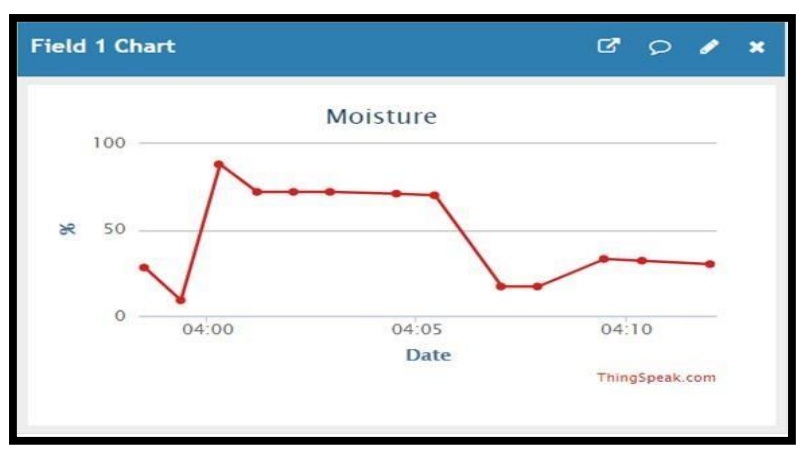

Fig. 16 - Soil Moisture Result via ThingSpeak Graph

For better monitoring process, the results were shown in graph form via ThingSpeak. Fig. 16 illustrates the results retrieved from the cloud database. The readings can be viewed via smartphone.

Table 3 - Moisture Sensor Result (Good)

\begin{tabular}{|c|c|c|c|c|c|}
\hline 28 & 2018-10-2: & 27 & 61 & 33 & 7 GOOD \\
\hline 29 & $2018-10-2$ & 28 & 59 & 56 & 6 GOOD \\
\hline 30 & $2018-10-2$ & 29 & 57 & -53 & 6 GOOD \\
\hline 31 & $2018-10-2$ & 30 & 56 & -52 & 6 GOOD \\
\hline 32 & $2018-10-2$ & 31 & 55 & 58 & $6 \mathrm{GOOD}$ \\
\hline 33 & $2018-10-2$ & 32 & 54 & 58 & 6 GOOD \\
\hline 34 & $2018-10-2$ & 33 & 53 & 58 & 6 GOOD \\
\hline 35 & $2018-10-2$ & 34 & 52 & 58 & 6 GOOD \\
\hline 36 & $2018-10-2$ & 35 & 51 & 58 & 5 GOOD \\
\hline 37 & $2018-10-2$ & 36 & 50 & 58 & 4 GOOD \\
\hline
\end{tabular}

Table 3 illustrates the moisture sensor reading for good soil moisture status. The result shows the moisture readings are between $50 \%$ to $61 \%$. As referred to the Appendix, it means the moisture status is good, and the plant can thrive. Therefore, the farmer does not need to take any corrective action. 
Table 4 - pH Sensor Result

\begin{tabular}{|c|c|c|c|c|c|}
\hline created_at & entry_id & Moisture & Tilt & $\mathrm{pH}$ & pH Status \\
\hline $2018-10-23$ 21:20:12 & 1 & 21 & 22 & 0 & Too Acidic \\
\hline $2018-10-23$ 21:21:41 & 2 & 24 & -6 & & Too Acidic \\
\hline 2018-10-23 21:23:17 & 3 & 22 & -6 & 2 & Too Acidic \\
\hline 2018-10-23 21:24:51 & 4 & 85 & 22 & 3 & Too Acidic \\
\hline $2018-10-23$ 21:25:46 & 5 & 37 & 28 & 3 & Too Acidic \\
\hline 2018-10-23 21:27:11 & 6 & 37 & 34 & 3 & Too Acidic \\
\hline $2018-10-23$ 21:28:06 & 7 & 92 & 3 & 4 & Acidic \\
\hline 2018-10-23 21:29:34 & 8 & 50 & 6 & 5 & Acidic \\
\hline 2018-10-23 21:30:28 & 9 & 51 & 6 & 6 & Acidic \\
\hline 2018-10-23 21:31:21 & 10 & 51 & 6 & 6 & Acidic \\
\hline 2018-10-23 21:32:16 & 11 & 92 & -48 & 7 & Neutral \\
\hline 2018-10-23 21:33:12 & 12 & 84 & -47 & 6 & Acidic \\
\hline 2018-10-23 21:34:47 & 13 & 10 & -12 & 5 & Acidic \\
\hline 2018-10-23 21:35:40 & 14 & 37 & -21 & 4 & Acidic \\
\hline 2018-10-23 21:36:34 & 15 & 91 & -15 & 3 & Too Acidic \\
\hline 2018-10-23 21:38:14 & 16 & 18 & 7 & 3 & Too Acidic \\
\hline 2018-10-23 21:39:09 & 17 & 16 & 4 & 3 & Too Acidic \\
\hline 2018-10-23 21:39:53 & 18 & 16 & 4 & 3 & Too Acidic \\
\hline $2018-10-23 \quad 21: 40: 48$ & 19 & 15 & 6 & 3 & Too Acidic \\
\hline
\end{tabular}

Table 4 shows the result obtained from the $\mathrm{pH}$ sensor. Based on the testing, the sensor able to read the $\mathrm{pH}$ level of the soil sample. From the displayed result, most of the reading is less than 7; therefore, the soil is categorized under acidic. As referred to the Appendix 1, soil with status 3.5 and above are suitable for palm oil planting. However, if the reading less than 3.5, it is categorized under too acidic. Therefore, the farmer needs to take appropriate action to treat the soil, such as mixing the flowing water to the soil with chalk.

Results also can be viewed in graph form via ThingSpeak. Fig. 17 illustrates the result of the $\mathrm{pH}$ sensor, as shown in ThinkSpeak via smartphone.

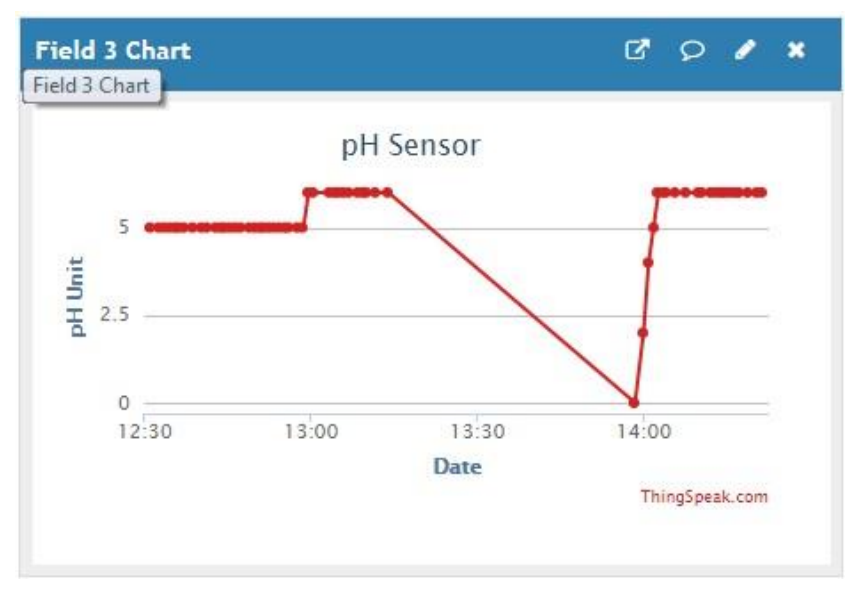

Fig. 17 - pH Result in ThingSpeak 
Table 5 - Tilt less than $25^{\circ}$

\begin{tabular}{|r|r|r|r|r|r|}
\hline 8 & $2018-10-2:$ & 7 & 92 & 3 & 4 \\
\hline 9 & $2018-10-2:$ & 8 & 50 & 6 & 5 \\
\hline 10 & $2018-10-2:$ & 9 & 51 & 6 & 6 \\
\hline 11 & $2018-10-2:$ & 10 & 51 & 6 & 6 \\
\hline 12 & $2018-10-2:$ & 11 & 92 & -48 & 7 \\
\hline 13 & $2018-10-2:$ & 12 & 84 & -47 & 6 \\
\hline 14 & $2018-10-2:$ & 13 & 10 & -12 & 5 \\
\hline 15 & $2018-10-2:$ & 14 & 37 & -21 & 4 \\
\hline 16 & $2018-10-2:$ & 15 & 91 & -15 & 3 \\
\hline 17 & $2018-10-2:$ & 16 & 18 & 7 & 3 \\
\hline 18 & $2018-10-2:$ & 17 & 16 & 4 & 3 \\
\hline 19 & $2018-10-2:$ & 18 & 16 & 4 & 3 \\
\hline 20 & $2018-10-2:$ & 19 & 15 & 6 & 3 \\
\hline
\end{tabular}

Table 6 - Tilt more than $25^{\circ}$

\begin{tabular}{|c|c|c|c|c|c|}
\hline 32 & $2018-10-2$ & 31 & 55 & 58 & 6 \\
\hline 33 & $2018-10-2$ & 32 & 54 & 58 & 6 \\
\hline 34 & $2018-10-2$ & 33 & 53 & 58 & 6 \\
\hline 35 & 2018-10-2: & 34 & 52 & 58 & 6 \\
\hline 36 & $2018-10-2$ & 35 & 51 & 58 & 5 \\
\hline 37 & $2018-10-2$ & 36 & 50 & 58 & 4 \\
\hline 38 & $2018-10-2$ & 37 & 88 & 52 & 3 \\
\hline 39 & $2018-10-2$ & 38 & 80 & 49 & 3 \\
\hline 40 & $2018-10-2$ & 39 & 79 & 52 & 2 \\
\hline 41 & $2018-10-2$ & 40 & 79 & 52 & 2 \\
\hline 42 & $2018-10-2$ & 41 & 79 & 52 & 2 \\
\hline 43 & $2018-10-2$ & 42 & 79 & 52 & 2 \\
\hline 44 & 2018-10-2: & 43 & 79 & 52 & 2 \\
\hline
\end{tabular}

Table 5 shows the result of the tilt sensor with tilt less than 25 degrees. While Table 6 shows the result of tilt more than 25 degrees. If the tilt is less than 25 degree, therefore the soil is suitable for palm oil planting. However, if the tilt is more than 25 degree, the soil is not suitable to plan the palm oil tree because the palm oil tree's root cannot hold the ground in more extended time. Therefore, the farmer needs to cut off the cliff into a terrace shape.

\section{Conclusion and Further Work}

In this project, the design and deployment of the real-time palm oil soil system for smart agriculture had been presented. The readings of the $\mathrm{pH}$, moisture and tilt of the soil samples will be later on displayed via smartphone. It can be concluded that this project had been successfully implemented.

For further work, it is recommended to replace the tilt sensor with Accelerometer sensor or gyroscope sensor. The result will be more accurate by using the sensor. Next, use LoRA instead of using Wireless Fidelity (Wi-Fi) for better coverage.

\section{Acknowledgement}

We thank Mr. Khairul Ismadi Ismail and Mr. Hasnan Baharum Izhar from Tabung Haji Plantation for evaluating the conditions of the soil. Also to Universiti Kuala Lumpur for supporting and sponsoring the cost of the project. 


\section{APPENDIX 1}

\begin{tabular}{|c|c|c|c|}
\hline Sensor & Moisture & Tilt & pH \\
\hline Best Value & $30 \%-75 \%$ & Below $25^{\circ}$ & 3.5 and 10 (pH unit) \\
\hline Condition & $\begin{array}{l}30 \%=\text { Soil too dry } \\
30 \%-75 \%=\text { Soil in good condition } \\
75 \% \text { and above = Soil too wet }\end{array}$ & $\begin{array}{l}0^{\circ}-25^{\circ} \\
25^{\circ}\end{array}$ & $\begin{array}{l}0-<3.5=\text { Soil too Acidic } \\
3.5-6=\text { Acidic } \\
7=\text { Neutral } \\
7-14=\text { Alkaline }\end{array}$ \\
\hline Effect & $\begin{array}{l}\text { Soil too dry: } \\
\text {-Palm oil will not get enough water to growth } \\
\text {-The leaves will turn into yellow } \\
\text { Soil too wet: } \\
\text {-Air cannot get into the root } \\
\text {-The plant will die in } 6 \text { month }\end{array}$ & $\begin{array}{l}25^{\circ} \text { and above: - } \\
\text { The plam oil root } \\
\text { cannot hold the } \\
\text { ground in longer } \\
\text { term }\end{array}$ & $\begin{array}{l}\text { Soil too acidic: } \\
\text {-Acidic soil not good for } \\
\text { planting any plant } \\
\text {-The plant infertile } \\
\text { Soil in alkaline condition: - } \\
\text { Good in planting any plant }\end{array}$ \\
\hline Solution & $\begin{array}{l}\text { Soil too dry: } \\
\text {-Open water gate to floe the water from river } \\
\text { or lake to plantation } \\
\text { Soil too wet: } \\
\text {-Use water pump to suck water out from } \\
\text { plantation to river }\end{array}$ & $\begin{array}{l}25^{\circ} \text { and above: - } \\
\text { Cut the cliff into } \\
\text { terrace shape } \\
\text { (stairs shape) }\end{array}$ & $\begin{array}{l}\text { Soil too acidic: } \\
\text {-Mix the water that flow to } \\
\text { the soil with chalk or alkaline } \\
\text { substances }\end{array}$ \\
\hline Contact & $\begin{array}{l}\text { 1) Mr. Khairul Ismadi Ismail } \\
\text { Senior Manager (Agronomist) at TH Plantation } \\
\text { Bhd (THP)(HQ Kuala Lumpur) } \\
\text { https://my.linkedin.com/in/khairul- } \\
\text { ismadiismail-82a8a2b9 } \\
\text { 2) Mr. Hasnan Baharum Izhar } \\
\text { Senior Manager (Plantation) at THP Plantation } \\
\text { Bhd(THP)(Ladang Gedung Sarawak) } \\
+60128852884\end{array}$ & & \\
\hline
\end{tabular}

*Disclaimer: The result is based on interview conducted with Agronomists at TH Plantation.

\section{Voltage to $\mathrm{pH}$ Value}

\begin{tabular}{|l|l|l|l|}
\hline voltaCE (mV) & pH va1ue & voLTAGE $(\mathrm{mV})$ & pH va1ue \\
\hline 414.12 & 0.00 & -414.12 & 14.00 \\
\hline 354.96 & 1.00 & -354.96 & 13.00 \\
\hline 295.80 & 2.00 & -295.80 & 12.00 \\
\hline 236.64 & 3.00 & -236.64 & 11.00 \\
\hline 177.48 & 4.00 & -177.48 & 10.00 \\
\hline 118.32 & 5.00 & -118.32 & 9.00 \\
\hline 59.16 & 6.00 & -59.16 & 8.00 \\
\hline 0.00 & 7.00 & 0.00 & 7.00 \\
\hline
\end{tabular}




\section{References}

[1] Chaudhary D.D and Nayse S.P. (2011). Application of Wireless Sensor Networks for Greenhouse Parameter Control in Precision Agriculture. International Journal of Wireless and Mobile Networks, 3(1), 140

[2] Maria C., Jesus M., Portocarrero T., Cesar D. G, Cristihian B., Jorge Luis T., Claudio Miceli de F. (2017). PalmNET: an open-source wireless sensor network for oil palm plantations, 4th International Conference on Networking, Sensing and Control (ICNSC), Calabria, Italy

[3] Anitha R., Suresh D., Gnaneswar P. et al. (2019). IoT Based Automatic Soil Moisture Monitoring System using Raspberry PI. International Journal of Innovative Technology and Exploring Engineering, 9, 4375-4379

[4] Kalaivani T., Allirani A., and Priya P., (2011). A survey on Zigbee based wireless sensor networks in agriculture. TISC 2011 - Proceedings of the 3rd International Conference on Trendz in Information Sciences and Computing

[5] Liu H., Meng Z., and Cui S., (2007). A wireless sensor network prototype for environmental monitoring in greenhouses, International Conference on Wireless Communications, Networking and Mobile Computing

[6] Province H., (2011). The temperature humidity monitoring system of soil based on wireless sensor networks, 3-6

[7] Hwang J., Shin C., and Yoe H., (2010). Study on an Agricultural Environment Monitoring Server System using Wireless Sensor Networks

[8] Wi-Fi Module. Available: https://www.sparkfun.com/products/13678 [Accessed: January 2019] 